\title{
Uso de recursos didáticos em atividades de Modelagem Matemática: uma análise de relatos de experiência
}

\author{
Use of teaching resources in Mathematical Modeling activities: an analysis of \\ experience reports
}

\author{
Adriana Ferreira Mendonça \\ Hermínio Borges Neto
}

\begin{abstract}
Resumo: Neste artigo busca-se identificar os recursos didáticos evidenciados em atividades de Modelagem Matemática e verificar em que situações eles são inseridos no planejamento docente. Definem-se, com efeito, as categorias recursos planejados e recursos emergentes. A pesquisa qualitativa, exploratória, de caráter bibliográfico, foi realizada em anais de dois congressos Encontro Paranaense de Modelagem na Educação Matemática (EPMEM) e Conferência Nacional sobre Modelagem na Educação Matemática (CNMEM) — que têm a Modelagem Matemática como escolha de publicação, tomando-se os relatos de experiência. Os resultados mostram que diversos meios são utilizados pelos professores e, na maioria das vezes, planejados, mas, em algumas situações, emergem da necessidade da investigação no encaminhamento da atividade pelos
\end{abstract} estudantes, o que, neste caso, demanda do professor maior preparo e mais cuidado na condução de atividades de Modelagem.

Palavras-chave: Modelagem Matemática. Recursos Didáticos. Planejamento.

Abstract: This article seeks to identify the teaching resources evidenced in Mathematical Modeling activities and to verify in which situations they are inserted in the teaching planning. Indeed, the categories defined are planned resources and emerging resources. The qualitative, exploratory, bibliographic research was carried out in the proceedings of two congresses - Encontro Paranaense de Modelagem na Educação Matemática (EPMEM) e Conferência Nacional sobre Modelagem na Educação Matemática (CNMEM) which have Mathematical Modeling as their publication choice, taking the experience reports. The results show that several means are used

Adriana Ferreira Mendonça Doutoranda em Educação. Professora da Escola de Ensino Médio Governador Adauto Bezerra, em Fortaleza. Ceará, Brasil. (iD) orcid.org/0000-0001-7609-4048 $\bowtie$ drika@multimeios.ufc.br Hermínio Borges Neto Doutor em Matemática. Professor do Programa de Pós-Graduação em Educação da Universidade Federal do Ceará (UFC). Ceará, Brasil.

iD orcid.org/0000-0003-4854-6953 $\bowtie$ herminio@multimeios.ufc.br

Recebido em 16/05/2020 Aceito em 09/06/2020 Publicado em 09/07/2020 by teachers and, in most cases, planned, but, in some situations, they emerge from the need for investigation in the forwarding of activity by students, which, in this case, demands greater preparation from the teacher and more care in conducting Modeling activities.

Keywords: Mathematical Modeling. Didactic resources. Planning.

\section{Introdução}

O emprego de materiais e equipamentos didáticos em atividades de Matemática registra importância já validada por diversos autores (PASSOS, 2009; FORTUNA, 2003; SOUZA, 2007). Esta relevância tem destaque principalmente na condição facilitadora da aprendizagem dos 
estudantes, implicando a compreensão e assimilação dos conteúdos. É muito recorrente, em planejamentos de aulas, se observar que os recursos mais comuns são, ainda, o livro didático, a lousa e o pincel. Muitas pesquisas, no entanto, mostram que a aplicação de outros meios que auxiliem os processos de ensino e de aprendizagem, especialmente na Matemática (SOUZA, 2010; ROBRIGUES e GAZIRE, 2012), se mostra cada vez mais eficaz e necessária nos espaços escolares.

Vídeos, músicas, filmes, jogos, computadores, Internet, livro didático, jornais, dentre outros, são recursos - ou ferramentas - que, ao serem cuidadosamente selecionados, contribuem para o desenvolvimento de aulas mais atraentes e motivam a participação dos estudantes na resolução dos problemas propostos.

Importa destacar o fato de que a utilização de recursos didáticos reclama estrita relação com os objetivos de ensino e, ainda, que estejam relacionados aos conteúdos matemáticos definidos para cada aula. Com efeito, é oportuno evidenciar que "a formação de professores no tocante ao uso dos recursos didáticos para o ensino de matemática, tanto inicial quanto continuada, enfrenta problemas e que os egressos podem não considerar critérios relevantes na escolha e uso desses recursos em sua prática" (PASSOS e TAKAHASHI, 2018, p. 186).

No referente à Modelagem Matemática, o desenvolvimento de atividades requer, muitas vezes, o emprego de recursos diversos, haja vista o caráter investigativo e exploratório que esta proposta de ensino abrange. Nossas leituras indicam que a escolha do material, que está condicionada ao tema desenvolvido na propositura de cada matéria, emerge da necessidade de os estudantes realizarem as pesquisas na construção de uma solução para cada problema.

A opção pelos recursos didáticos em atividades de Modelagem Matemática é, portanto, um aspecto que também requer atenção do professor em seu planejamento. Assim como os temas que despontam mediante o interesse dos estudantes, ou os conteúdos matemáticos que surgem por intermédio das discussões ou dos caminhos trilhados na resolução dos problemas, a tomada consentânea dos recursos para mediar os processos de resolução deve ser observada com muita cautela pelos professores.

Refletindo acerca do emprego de recursos didáticos em atividades de Modelagem Matemática, surgiram alguns questionamentos: Que recursos didáticos são mobilizados em atividades de Modelagem Matemática? Em que momento da atividade eles são requeridos? Há alguma intencionalidade em seu emprego? Seu uso é planejado pelo professor? 
Com efeito, buscando respostas para nossos questionamentos, neste artigo temos por objetivo identificar os recursos didáticos evidenciados em atividades de Modelagem Matemática e verificar em que situações eles são inseridos no planejamento docente. Esta configura, pois, uma pesquisa de abordagem qualitativa, do tipo bibliográfica. Nossa busca se deu em artigos de eventos com enfoque na Modelagem Matemática - Encontro Paranaense de Modelagem na Educação Matemática (EPMEM) e Conferência Nacional sobre Modelagem na Educação Matemática (CNMEM) - notadamente, os relatos de experiência.

Iniciamos com uma discussão na literatura acerca do que são recursos didáticopedagógicos, reportando-nos à sua importância em atividades de Modelagem. Em seguida, indicamos o percurso metodológico a fim de escolher os relatos, procedendo, na sequência, à descrição dos resultados e, como remate, apresentamos uma seção denominada Considerações.

\section{Recursos didáticos}

É bastante habitual, nos espaços escolares, o uso das expressões recursos didáticos, recursos pedagógicos ou, ainda, recursos didático-pedagógicos. Precisamos, inicialmente, atentar para a ideia de que a caracterização dessas expressões é importante para a análise impressa neste artigo, de modo a amparar os estudos ora procedidos. Deste modo, consideramos alguns autores (SOUZA, 2007; FREITAS, 2009; EITERER e MEDEIROS, 2010) que ofertam definições para esses conceitos.

De acordo com Souza (2007, p. 111), a dicção recursos didáticos representa "todo material utilizado como auxílio no ensino-aprendizagem do conteúdo proposto para ser aplicado pelo professor a seus alunos". São, portanto, veículos aos quais recorre o professor. Tem-se, ainda, a compreensão de que "os materiais e equipamentos didáticos são todo e qualquer recursos utilizado em um procedimento de ensino, visando à estimulação do aluno e à sua aproximação do conteúdo" (FREITAS, 2009, p. 21). Em ambas as situações, os autores destacam o papel de estabelecer relação entre os conteúdos de ensino e os estudantes, tendo, na mediação, o concurso do professor.

Para Eiterer e Medeiros (2010), recursos pedagógicos se referem ao "entendimento daqueles lugares, profissionais, processos e materiais que visem assegurar a adaptação recíproca dos conteúdos a serem conhecidos aos indivíduos que buscam conhecer." (p. 1). Elas ampliam o entendimento, explicando que recurso pedagógico "é o que auxilia a aprendizagem, de quaisquer 
conteúdos, intermediando os processos de ensino-aprendizagem intencionalmente organizados por educadores na escola ou fora dela" (EITERER e MEDEIROS, 2010, p. 1) Para essas autoras, existem materiais criados especificamente com esse propósito - laboratório de ensino de Ciências, materiais didáticos (livro didático, softwares) - e outros cuja função pedagógica é adquirida mediante o interesse docente em utilizá-los — jornais, histórias em quadrinhos, música ou documentários.

Consoante reforça Freitas (2009), muitos dos materiais didáticos "foram criados exclusivamente para fins pedagógicos, isto é, foram pensados para serem didáticos, para mediarem a construção do conhecimento que ocorre no ambiente escolar" (p. 22). A proposta pedagógica da escola, do professor, é que direciona a escolha dos materiais didáticos que poderão expandir as opções de experiência dos estudantes e efetivar sua aprendizagem.

O termo pedagógico - e isto é oportuno expressar — está relacionado às finalidades que são, em sua medida, educativas, incorporando o sentido do adjetivo didático, a depender do tipo de material que esteja sendo aplicado. Os materiais utilizados para facilitar o ensino e a aprendizagem são, portanto, didáticos com propósito pedagógico.

A expressão recursos didático-pedagógicos nos parece, por conseguinte, que expressa 0 real sentido do emprego de materiais e equipamentos no intento de promover a motivação discente e sua aproximação do conteúdo. São, reiterando o que expusemos, instrumentos para os quais 0 docente recorre, visando a facilitar o ensino e favorecer a aprendizagem, tendo, ipso facto, um caráter instrutivo e educacional.

De tal modo, o apelo aos recursos didáticos está associado à intencionalidade docente em buscar a motivação dos estudantes em sua aprendizagem. Demais disso, carrega a noção de que "utilizar recursos didáticos no processo de ensino-aprendizagem é importante para que 0 aluno assimile o conteúdo trabalhado, desenvolvendo sua criatividade" (SOUZA, 2007, p. 112113).

Além desses aspectos, os recursos didáticos devem propiciar ao professor alguma reflexão acerca de seu alcance, relativamente aos objetivos estipulados em plano de aula. Por seu intermédio, também cabe aos estudantes proceder à reflexão a respeito dos resultados que esses recursos podem ensejar na elaboração de conceitos, aprofundamento dos conteúdos, interação com os colegas e na organização do pensamento crítico. Deve-se considerar que a ação proposta por meio de recursos didáticos "seja reflexiva e que o aluno aprenda de modo significativo, 
desenvolvendo atividades nas quais raciocine, compreenda, elabore e reelabore seu conhecimento, sendo que o uso de materiais pode trazer uma grande contribuição nesse sentido" (FIORENTINI e MIORIM, 1990, p. 6).

Efetivamente, pois, para ser reflexiva, a proposta pedagógica que considera o uso de recursos didáticos há de prever situações propiciadoras de uma abordagem com sentido para 0 estudante. Indicamos, como exemplos: que tipos de representações serão requeridas em seu emprego, como a linguagem associada ao recurso pode demandar a transição de representações ou, ainda, analisar o potencial significativo para a aprendizagem com algum tipo de jogo. Nesse último apontamento, evidencia-se o fato de que, "enquanto joga, o aluno desenvolve a iniciativa, a imaginação, o raciocínio, a memória, a atenção, a curiosidade e o interesse, concentrando-se por longo tempo em uma atividade" (FORTUNA, 2003, p. 3).

De tal maneira, orientações para o uso adequado de materiais didáticos são frequentes na literatura. Dentre as várias proposituras evidenciadas, apontamos duas relacionadas a esse aspecto em discussão — da promoção de uma aprendizagem reflexiva: "realizar uma escolha responsável e criteriosa do material; [e] planejar com antecedência as atividades, procurando conhecer bem os recursos a serem utilizados, para que possam ser explorados de forma eficiente" (RÊGO, M. e RÊGO, G. 2009, p. 54). Segundo esses autores, os recursos devem ser adequados aos interesses discentes e, além disso, o professor há de prever mudanças no processo de ensino.

Assim, cabe ao professor a escolha intencional e consciente de recursos didáticos, considerando o fato de que sua utilização está associada, também, ao desenvolvimento cognitivo dos estudantes nas diversas possibilidades de percepção e compreensão discentes manipulação, produção ou experimentação — tendo claro que "esses materiais devem servir como mediadores para facilitar a relação professor/aluno/conhecimento no momento em que um saber está sendo construído" (PASSOS, 2009. p. 78).

Cabe considerar, deste modo, que o emprego de recursos didáticos tem foco em estabelecer vínculos entre os estudantes e os conteúdos, devendo ser planejados com o propósito de alcançar os objetivos previstos pelo professor. Assim, impende se atentar para o fato de que "o uso inadequado de um recurso didático pode resultar em uma inversão didática em relação à sua finalidade pedagógica inicial" (PAIS, 2000, p. 5), ou seja, é preciso que o emprego de recursos didáticos tenha finalidade e intencionalidade.

O caráter didático e pedagógico dos materiais de apoio ao professor deve ser observado 
na organização dos processos de ensino e de aprendizagem, estando claro que apenas seu emprego não garante a aprendizagem. É preciso, pois, o uso planejado, consciente, criativo e intencional da abordagem dos conteúdos, para que as possibilidades de aprendizagem dos estudantes sejam ampliadas.

\section{Modelagem Matemática}

A Modelagem Matemática é considerada, por alguns autores, um recurso para motivar estudantes em sua aprendizagem. Em Fernandes e Santos Júnior (2012) observamos a percepção da Modelagem Matemática como recurso pedagógico para o ensino de Matemática. Em Werlich (2008), a Modelagem surge como recurso didático-pedagógico. Em Honorato (2015), sua caracterização no contexto escolar é de uma ferramenta que tira o aluno da condição de espectador passivo. Por fim, em Reis (2016), seu emprego em aulas de Biologia é indicado como recurso metodológico possível de contribuir para aprendizagem dos estudantes. Nosso entendimento é o de que Modelagem Matemática é alternativa de ensino e de aprendizagem (BURAK, 1992) que, mediante planejamento, pode demandar algum tipo de recurso didático para sua implementação.

Uma das características fundamentais da Modelagem é o fato de que, no desenvolvimento das atividades, as ações dos estudantes, geralmente, guiam o andamento da aula. A escolha do tema de investigação, por exemplo, deve ser, prioritariamente, direcionada pelos estudantes. Nesse raciocínio, Burak (1992) evidencia que o interesse do grupo e a obtenção de informações e dados do ambiente são dois princípios relevantes na condução de atividades de Modelagem Matemática.

Na proposta de Barbosa (2001), está prevista uma organização mais estruturada que permite a implementação da Modelagem, mesmo com professores que estejam iniciando esse tipo de proposta de ensino. Embora se mantenha o interesse dos estudantes, o autor ainda deixa sob responsabilidade docente as intervenções iniciais, tais como a escolha do problema e a seleção dos dados. No caso 1, o professor exibe o problema e os dados, cabendo ao aluno a investigação para resolução deste problema. No de número 2, o professor expõe o problema e os alunos se encarregam, tanto da coleta dos dados, quanto da investigação para resolvê-lo. Por fim, no caso 3, os alunos são responsáveis, juntamente com o professor, pela escolha do tema, elaboração das hipóteses e resolução do problema. 
Nessa perspectiva, devemos pensar que o desenvolvimento de atividades de Modelagem Matemática, como qualquer proposta pedagógica, envolve o planejamento das ações que serão implementadas com os estudantes. Esse planejamento, geralmente, pressupõe uma ordem lógica das ações que serão desenvolvidas na aula regular com previsão do tempo para cada etapa, recursos que serão empregados, dentro outros aspectos.

Considera-se, também, que o planejamento docente deve englobar a preparação ou análise do ambiente - informações acerca da escola, recursos didáticos disponíveis - e uma análise teórica relativa à seleção dos conteúdos de ensino, objetivos da aula, conhecimentos prévios dos estudantes (SOUSA, 2015).

Para o planejamento das atividades de Modelagem, Mendonça e Lopes (2015) apresentam o princípio da organização, que prevê situações de ordem prática: "questões de currículo, conteúdo e tempo de duração de todo o trabalho e de suas etapas; e critérios para a formação de grupos e obtenção de material e de autorizações diversas" (p. 11-12). Com isto, o professor atenta para as especificidades do contexto escolar e pode criar um ambiente ou panorama propício ao ensino e aprendizagem, reduzindo as dificuldades operacionais da atividade.

$\mathrm{Na}$ Modelagem, evidencia-se que "os conceitos e ideias matemáticas exploradas dependem do encaminhamento que só se sabe à medida que os alunos desenvolvem a atividade". (BARBOSA, 2001, p. 5). Além disso, "quando os alunos estão explorando um cenário, o professor não pode prever que questões vão aparecer" (SKOVSMOSE, 2000, p. 18). Assim, a obtenção de um modelo matemático poderá seguir trilhas distintas e demandar conceitos matemáticos diversos que terão relação com o nível de conhecimento dos estudantes e com a mediação docente.

De tal modo, outro ponto a considerar no planejamento das aulas com proposta de Modelagem é o cumprimento do plano de aula - ou do currículo definido no sistema de ensino. Considerando que o professor pode não prever algumas ações no decorrer da aula com Modelagem, conceitos matemáticos não definidos, inicialmente, no plano de aula podem ser requeridos para que a solução do problema seja encaminhada. Deste modo, uma sistematização preliminar pode favorecer os dois aspectos: cumprir o plano de aula e lidar com situações adversas no surgimento de conteúdos não estipulados neste plano.

Pensar um planejamento diferenciado, com atividades mais diversificadas, denota para 0 professor trabalhar numa situação de risco em oposição a uma circunstância de conforto na qual 
estão sedimentadas suas ações. Skovsmose (2008), que se refere a zonas de risco e de conforto, explica que, na primeira, há pouca previsibilidade e não existe segurança nas situações de sala de aula, embora seja uma oportunidade para os desafios e para a aprendizagem. Assim, quando o professor opta por nela trabalhar, mesmo limitando a definição de um planejamento mais estruturado, ele abre espaço para a criatividade discente.

Na Modelagem Matemática, efetivamente, os recursos têm funções muito diversificadas. Podem servir para expressar um tema de investigação, fomentar a curiosidade dos estudantes acerca de algum assunto, bem como obter informações e proceder a coleta e análises de dados que implicarão na tomada de decisão e na elaboração do modelo matemático.

Alguns autores preveem o uso de recursos em atividades de Modelagem. Bassanezi (2002), por exemplo, orienta os iniciantes nesta tendência que estruturem os dados por meio de algum tipo de contagem ou medição e, com isto, uma tabela de dados, ou um sistema cartesiano, facilitará a visualização do fenômeno investigado; Dalla Nina (2005) direciona as atividades por meio de tecnologias acessíveis aos estudantes; Domingues (2014) destaca o papel dos vídeos nos trabalhos de Modelagem, indicando que podem "servir de fonte de pesquisa dos temas, referência bibliográfica e meio de divulgação durante os diferentes processos de desenvolvimento dos trabalhos de Modelagem" (p. 106).

Cabe considerar, no entanto, o fato de que em alguns contextos o planejamento pode não funcionar integralmente com projetos de Modelagem em razão da particularidade dessa proposta de ensino, em que os sujeitos dependem das ações procedentes do processo investigativo. Embora este fato não invalide o desenvolvimento das etapas de um ciclo de Modelagem, 0 professor deve estar preparado para situações não planejadas que serão desencadeadas na investigação do tema definido por ele ou pelo grupo de estudantes.

Essas situações têm, por conseguinte, implicações na escolha dos recursos didáticos, e essa não será definida no planejamento da aula, mas mediante as interações com os estudantes, com o tema da investigação e sua problematização. Estes aspectos devem ser percebidos pelo professor que busca realizar atividades de Modelagem.

Assim, definimos dois tipos de situações nas quais o professor utiliza os recursos didáticos: a primeira é a planejada, quando é possível prever os materiais necessários na atividade, ao passo que a outra é a emergente, quando os estudos que direcionam a investigação demandam materiais não previstos inicialmente, mas que serão relevantes para os resultados da 
elaboração do modelo matemático. Deste modo, temos os recursos planejados e os emergentes.

\section{Trajetória metodológica}

Este artigo corresponde à uma pesquisa exploratória de cunho bibliográfico, conforme indicado em Gil (2008). Para identificar os recursos didáticos em atividades de Modelagem Matemática e em qual situação eles são inseridos no planejamento docente, decidimos, como critério de inclusão, que os artigos a serem analisados deveriam ser relatos de experiência (RE), por serem categorias de textos científicos que descrevem precisamente uma dada experiência, estabelecendo relações entre prática e teoria.

A escolha dos relatos se deu por meio de buscas em anais de eventos que abordassem a temática Modelagem Matemática, considerando suas últimas edições - CNMEM (2019) e EPMEM (2018). Desse modo, a tomada inicial foi feita mediante os critérios: temática Modelagem Matemática, relato de experiência, última edição de cada evento. Nessa ocasião, se catalogaram o total de 88 relatos.

No segundo momento, foram lidos todos os títulos, resumos e palavras-chave para a definição dos relatos que seriam submetidos à análise, sendo o critério de inclusão a indicação prévia de algum recurso didático utilizado na atividade relatada. Os termos identificados foram: recursos didáticos, recursos pedagógicos, vídeo, áudio, planilha, software, site, aplicativo, diário de campo, livro didático - ou qualquer palavra que remetesse seu emprego à condição de recurso didático, no enfoque de Sousa (2007), na atividade com Modelagem Matemática. Após esta fase, restaram 45 relatos de experiência.

Em seguida, no terceiro momento foi feita a leitura integral de todos os relatos à luz de nossa interrogação de pesquisa. Com atenção mais rigorosa na descrição de cada experiência relatada, o critério de exclusão para esta fase foi a não correspondência do recurso indicado no título ou no resumo com a experiência relatada, ou seja, o recurso serviu para registro do pesquisador e não para o desenvolvimento da atividade de Modelagem. Com isso, permaneceram 33 textos, indicados no Quadro 1 a seguir. 
Quadro 1: Textos considerados para investigação

\begin{tabular}{|c|c|c|c|}
\hline Código & Título do artigo & Autores & Evento \\
\hline RE1 & $\begin{array}{l}\text { Reflexões sobre uma atividade de } \\
\text { Modelagem Matemática: jogos olímpicos e } \\
\text { seus recordes }\end{array}$ & $\begin{array}{l}\text { Dallan Marcelo Gregório; Aline } \\
\text { Vaccari; Dionísio Burak }\end{array}$ & EPMEM \\
\hline RE2 & $\begin{array}{l}\text { Conceitos probabilísticos: uma construção } \\
\text { baseada no diálogo em uma atividade de } \\
\text { Modelagem Matemática }\end{array}$ & $\begin{array}{l}\text { Alexandre Nascimento; Oscar Luiz } \\
\text { Teixeira de Rezende; Luciano } \\
\text { Lessa Lorenzoni }\end{array}$ & EPMEM \\
\hline RE3 & $\begin{array}{l}\text { Mandala: relato de experiência de uma } \\
\text { atividade de Modelagem Matemática }\end{array}$ & $\begin{array}{l}\text { Carina Chulek; Silvia Regina } \\
\text { Potulski dos Santos; Dionísio } \\
\text { Burak }\end{array}$ & EPMEM \\
\hline RE4 & $\begin{array}{l}\text { Modelagem Matemática e bicicleta: uma } \\
\text { experiência no ensino da Matemática }\end{array}$ & $\begin{array}{l}\text { Marcela Camila Picin de Melo; } \\
\text { Andresa Maria Justulin; Karina } \\
\text { Alessandra Pessoa da Silva }\end{array}$ & EPMEM \\
\hline RE5 & $\begin{array}{l}\text { "Tinha um barranco no meio do caminho, no } \\
\text { meio do caminho tinha um barranco": } \\
\text { investigando e aprendendo por meio da } \\
\text { Modelagem Matemática }\end{array}$ & $\begin{array}{l}\text { Edineia dos Santos Brizola Brum; } \\
\text { Izabela Badaro Machado de } \\
\text { Oliveira; Valquíria Dutra Leite }\end{array}$ & EPMEM \\
\hline RE6 & $\begin{array}{l}\text { Do aeroporto à sala de aula: aterrissar em } \\
\text { Toledo ou Cascavel? }\end{array}$ & $\begin{array}{l}\text { Djerly Simonetti; Maiara Cristina; } \\
\text { Rodolfo Eduardo Vertuan }\end{array}$ & EPMEM \\
\hline RE7 & $\begin{array}{l}\text { Investigando o aquecimento do } \\
\text { computador: uma atividade de Modelagem } \\
\text { Matemática }\end{array}$ & $\begin{array}{l}\text { Kawana Fernando Rogoski; Karina } \\
\text { Alessandra Pessôa da Silva }\end{array}$ & EPMEM \\
\hline RE8 & $\begin{array}{l}\text { Novo acesso ao campus CEDETEG: um } \\
\text { estudo sob a luz da Modelagem Matemática } \\
\text { na Educação Matemática }\end{array}$ & $\begin{array}{lrr}\text { Kamila Gonçalves } & \text { Celestino; } \\
\text { Cheila Miranda } & \text { Tachevski; } \\
\text { Dionísio Burak } & \end{array}$ & EPMEM \\
\hline RE9 & $\begin{array}{l}\text { A vídeo-análise em fluidos: antecipação } \\
\text { para uma Modelagem Matemática }\end{array}$ & $\begin{array}{l}\text { Rodrigo Tavares da Silva; Adriana } \\
\text { Helena Borssoi; Caio Barreto de } \\
\text { Oliveira Reis }\end{array}$ & EPMEM \\
\hline RE10 & $\begin{array}{l}\text { O Paraná será o maior produtor de soja, em } \\
\text { ranking nacional, nos próximos anos? uma } \\
\text { atividade de Modelagem Matemática }\end{array}$ & $\begin{array}{l}\text { Simone Ribeiro da Silva; Tatiany } \\
\text { Mottin Dartora }\end{array}$ & EPMEM \\
\hline RE11 & $\begin{array}{l}\text { Dentre narrativas digitais: } 0 \\
\text { desenvolvimento da literacia digital por } \\
\text { meio do uso do Big Data }\end{array}$ & $\begin{array}{l}\text { Caroline Dal Agnol; Rodrigo Dalla } \\
\text { Vecchia }\end{array}$ & EPMEM \\
\hline RE12 & $\begin{array}{l}\text { Vamos trocar figurinhas? Relato de uma } \\
\text { experiência com Modelagem Matemática } \\
\text { no sexto ano do Ensino Fundamental }\end{array}$ & $\begin{array}{l}\text { Larissa Bersan Mateus; Bárbara } \\
\text { Cândido Braz; Lilian Akemi Kato }\end{array}$ & EPMEM \\
\hline RE13 & $\begin{array}{l}\text { Modelagem Matemática aliada à } \\
\text { programação de computadores na } \\
\text { Educação Básica }\end{array}$ & $\begin{array}{l}\text { Felipe José Rezende de Carvalho; } \\
\text { Tiago Emanuel Klüber }\end{array}$ & EPMEM \\
\hline RE14 & $\begin{array}{l}\text { Modelagem Matemática no Ensino } \\
\text { Fundamental: uma possibilidade para } \\
\text { explorar o conceito de área }\end{array}$ & $\begin{array}{l}\text { Cláudia Tavares Barbosa dos } \\
\text { Santos; Kéliton José da Matta } \\
\text { Calheiros; Felipe José Rezende de } \\
\text { Carvalho }\end{array}$ & EPMEM \\
\hline
\end{tabular}




\begin{tabular}{|c|c|c|c|}
\hline RE15 & $\begin{array}{l}\text { Uma atividade de Modelagem Matemática } \\
\text { para a análise da germinação de semente } \\
\text { do pepino }\end{array}$ & $\begin{array}{l}\text { Marina Cunha Ferreira; Leandro } \\
\text { de Paula Ribeiro Pereira; Bárbara } \\
\text { Nivalda Palharini Alvim Sousa }\end{array}$ & EPMEM \\
\hline RE16 & Como fazer a pedra quicar na água? & $\begin{array}{l}\text { Adina Veronica Remor; Daniele } \\
\text { Gonçalves; Samara Schrenk }\end{array}$ & EPMEM \\
\hline RE17 & Que delícia! Vamos aprender com a pizza? & $\begin{array}{l}\text { Fernanda Celestino dos Santos } \\
\text { Espanhol; Elhane de Fatima } \\
\text { Fritsch Cararo; Roseli Edelamar } \\
\text { Waldof Costa }\end{array}$ & EPMEM \\
\hline RE18 & $\begin{array}{l}\text { A arte do futebol na Modelagem } \\
\text { Matemática }\end{array}$ & $\begin{array}{l}\text { Lenoar Eloi Cararo; Elhane de } \\
\text { Fátima Fritsch Cararo; Rubia Mara } \\
\text { Rubia Mara Pinheiro Schmitz; Inês } \\
\text { Graziela Dalmolin dos Santos }\end{array}$ & EPMEM \\
\hline RE19 & $\begin{array}{l}\text { BNCC e Modelagem Matemática: relato de } \\
\text { uma atividade desenvolvida com uma turma } \\
\text { do } 6^{\circ} \text { ano do Ensino Fundamental }\end{array}$ & Rhômulo Oliveira Menezes & CNMEM \\
\hline RE20 & $\begin{array}{l}\text { Matemática na exploração de um conceito } \\
\text { da Física: as possibilidades do uso dos } \\
\text { softwares Excel e GeoGebra na obtenção } \\
\text { do modelo matemático }\end{array}$ & $\begin{array}{l}\text { Márcia Jussara Hepp Rehfeldt; } \\
\text { Italo Gabriel Neide; Rosilene Inês } \\
\text { König; Silvana Emer; Vanessa } \\
\text { Brandão de Vargas }\end{array}$ & CNMEM \\
\hline RE21 & $\begin{array}{l}\text { Modelagem Matemática e dialogicidade: } \\
\text { uma parceria para as competências } \\
\text { estatística - coleta, análise e reflexões de } \\
\text { dados }\end{array}$ & $\begin{array}{l}\text { Marcelene Alves Duarte; Nathália } \\
\text { Maria Dias Pagung; Rodolfo } \\
\text { Chaves }\end{array}$ & CNMEM \\
\hline RE22 & $\begin{array}{l}\text { Modelagem com vídeos digitais: reflexões a } \\
\text { partir de um relato }\end{array}$ & $\begin{array}{l}\text { Neil da Rocha Canedo Junior; } \\
\text { Marcelo de Carvalho Borba }\end{array}$ & CNMEM \\
\hline RE23 & $\begin{array}{l}\text { Ensino de Matemática na Educação Infantil: } \\
\text { uma experiência por meio da Modelagem } \\
\text { Matemática }\end{array}$ & $\begin{array}{l}\text { Ana Caroline Zampirolli; Lilian } \\
\text { Akemi Kato }\end{array}$ & CNMEM \\
\hline RE24 & $\begin{array}{l}\text { Etapas da Modelagem a partir da animação } \\
\text { "Procurando Nemo" }\end{array}$ & $\begin{array}{l}\text { Rodolfo Chaves; Lucca Jeveaux } \\
\text { Oliveira Bonatto; Alexandre Krüger } \\
\text { Zocolotti; Larissa Toniato }\end{array}$ & CNMEM \\
\hline RE25 & $\begin{array}{l}\text { Cubagem de madeira com professores de } \\
\text { Matemática em serviço }\end{array}$ & $\begin{array}{l}\text { Danusa de Lara Bonotto; Morgana } \\
\text { Scheller }\end{array}$ & CNMEM \\
\hline RE26 & $\begin{array}{l}\text { O uso de agrotóxicos na plantação de } \\
\text { milho: uma atividade de Modelagem } \\
\text { Matemática }\end{array}$ & $\begin{array}{l}\text { Andréa Regina Teixeira } \\
\text { Nunomura; Luana Carvalho dos } \\
\text { Santos; Camila lorio Marton; } \\
\text { Karina Alessandra Pessoa da } \\
\text { Silva }\end{array}$ & CNMEM \\
\hline RE27 & $\begin{array}{l}\text { Modelagem Matemática, jogos e pedagogia } \\
\text { da pergunta: um caso de inclusão }\end{array}$ & $\begin{array}{l}\text { Gabriel de Souza Pinheiro; } \\
\text { Marilaine de Fraga Sant'Ana }\end{array}$ & CNMEM \\
\hline RE28 & $\begin{array}{l}\text { Somos o que comemos: percebendo a } \\
\text { Matemática no cotidiano }\end{array}$ & $\begin{array}{l}\text { Adriana Alves de Moraes Lima; } \\
\text { Kátia Maria de Medeiros }\end{array}$ & CNMEM \\
\hline
\end{tabular}




\begin{tabular}{|c|c|c|c|}
\hline RE29 & $\begin{array}{l}\text { Modelagem Matemática e Matemática } \\
\text { Fuzzy para a abertura de um } \\
\text { empreendimento }\end{array}$ & $\begin{array}{l}\text { Jeferson Takeo Padoan Seki; } \\
\text { Bárbara Nivalda Palharini de } \\
\text { Sousa; Tania Camila } \\
\text { Kochmanscky Goulart; Ademir } \\
\text { Pereira Junior; Daiany Cristiny } \\
\text { Ramos; Ariel Cardoso da Silva; } \\
\text { Lourdes Maria Werle de Almeida }\end{array}$ & CNMEM \\
\hline RE30 & $\begin{array}{l}\text { Projeto de desenvolvimento de produto em } \\
\text { uma atividade de Modelagem Matemática }\end{array}$ & $\begin{array}{l}\text { Thiago Fernando Mendes; } \\
\text { Kassiana Schmidt Surjus; Adriana } \\
\text { Helena Borssoi; Karina Alessandra } \\
\text { Pessoa da Silva }\end{array}$ & CNMEM \\
\hline RE31 & $\begin{array}{l}\text { Uma atividade de Modelagem Matemática } \\
\text { utilizando o software Tracker }\end{array}$ & $\begin{array}{l}\text { Cíntia da Silva; Amanda Faria de } \\
\text { Oliveira; Lays Silva Jeronimo }\end{array}$ & CNMEM \\
\hline RE32 & $\begin{array}{l}\text { A Modelagem Matemática numa } \\
\text { experiência didática com futuros } \\
\text { professores da UNEMAT: aplicação da } \\
\text { integral definida de uma variável real }\end{array}$ & $\begin{array}{l}\text { Polyanna Possani da Costa Petry; } \\
\text { Kátia Maria de Medeiros }\end{array}$ & CNMEM \\
\hline RE33 & $\begin{array}{l}\text { Os interpretantes em uma atividade de } \\
\text { Modelagem Matemática mediada pela } \\
\text { tecnologia }\end{array}$ & $\begin{array}{l}\text { Ariely Aparecida Caruzo; Michele } \\
\text { Regiane Dias Veronez }\end{array}$ & CNMEM \\
\hline
\end{tabular}

Fonte: Elaboração dos Autores

Após a seleção desses relatos, adentramos o quarto momento do estudo, no qual, mediante o emprego dos recursos didáticos pelos autores em suas narrativas, definimos duas categorias. As leituras nos fizeram perceber que algumas das ferramentas utilizadas eram definidas pelo professor (ou pesquisador) anteriormente a sua aplicação. Outras ferramentas, no entanto, eram requisitadas com base no interesse dos estudantes ou da necessidade da investigação. Deste modo, foi possível especificar duas categorias de análise, conforme segue.

- Recurso didático planejado: recursos evidenciados na proposta inicial da atividade de Modelagem Matemática e podem ser percebidos no título, no resumo, nas palavras-chave ou no decorrer do relato de experiência, de modo intencional. 0 emprego do recurso foi previsto no planejamento da ação pedagógica.

- Recurso didático emergente: recursos não previstos na ação docente; foram utilizados mediante a propositura da situação de investigação; sua indicação pode ser dada pelo professor ou se manifestar com amparo nas discussões e interesse dos estudantes.

\section{Discussão dos resultados}

Nossa opção foi por examinar relatos de experiência que explicitassem o emprego dos 
recursos didáticos em atividades de Modelagem Matemática. Importa destacar, por conseguinte, que tivemos o cuidado de observar, em cada relato, os recursos utilizados pelo pesquisador como fonte de registro para sua pesquisa - estes não são foco de nosso estudo, por isso foram excluídos - e aqueles empregados propriamente na atividade de Modelagem Matemática.

O Quadro 2 exibe todos os recursos utilizados nas atividades, mencionados nos relatos. Fácil é notar uma diversidade deles, e seu uso está relacionado a vários aspectos do processo investigativo, como busca de informações na exploração do tema, registro de dados e, ainda, confirmação ou contestação das hipóteses de pesquisa.

Quadro 2: Recursos utilizados nos RE de Modelagem Matemática

\begin{tabular}{|lll|}
\hline \multicolumn{3}{|c|}{ Recursos utilizados nos RE de Modelagem Matemática } \\
\hline Álbum de figurinhas [1] & Entrevista [2] & Narrativa digital [1] \\
Animação [1] & Fita métrica e trena [1] & Pipeta [1] \\
Artigo [1] & Folhas de jornal [1] & Produção textual [1] \\
Áudio (gravação) [2] & Formas geométricas [1] & Questionário [3] \\
Balança [1] & Fotos [1] & Recortes de jornais [1] \\
Bastão [1] & Folhas de jornal [1] & Relatório [1] \\
Bicicleta [1] & Google Correlate [1] & Sacos de terra [1] \\
Bolinhas de aço [1] & Google Maps [2] & Sapato/altura dos alunos [1] \\
Bula de herbicida [1] & Gráfico [3] & Semente de pepino [1] \\
Cartazes [1] & História [3] & Sistemas fuzzy [1] \\
Cola e fita adesiva [1] & Instrumentos de medida [3] & Sites [6] \\
Dado de seis faces [1] & Jogos [2] & Softwares e aplicativos [20] \\
Desenhos [2] & Malha quadriculada [1] & Tabela [9] \\
Diário de campo [3] & Mandala [1] & Vídeo [8] \\
Documentos [1] & Material de manipulação [1] & \\
\hline
\end{tabular}

De fato, observamos que, mediante a quantidade de recursos citada no Quadro 2, a condução de atividades de Modelagem possibilita o emprego de recursos diversos e que, em todos os casos, sua função pedagógica foi determinada pelo contexto da investigação no interesse docente e discente da prática.

É relevante evidenciar a recorrência ao computador em diversos relatos — quase metade da amostra em análise. A utilização de softwares e aplicativos para aparelhos celulares (smartphones) ou para computadores (Excel e Powerpoint) é bastante comum em diversas aplicações, sendo possível em distintas ocasiões ou atividades, como nos seguintes relatos: RE1, RE5, RE6, RE7, RE9, RE12, RE13, RE14, RE16, RE20, RE 29, RE30, RE31, RE32, RE33. 
Essa representatividade dos recursos tecnológicos nos relatos reforça o pensamento de que "a Modelagem Matemática, usando recursos da Informática, possa despertar o interesse do aluno pela Matemática e, consequentemente, para a sua importância e utilização" (DELLA NINA, 2005, p. 17). Isso denota que, especialmente no ensino de Matemática, a integração dos recursos didáticos em atividades de Modelagem pode contribuir positivamente na aprendizagem e no desenvolvimento da curiosidade dos estudantes.

Os softwares foram bem diversificados - GeoGebra, Tracker, Winplot, CurveExpert, MatLab, Scratch. Em cada relato, encontramos justificativas para seu uso: "para representação gráfica dos modelos obtidos" (RE6) ou "Os alunos utilizaram o Excel para identificar o tipo de gráfico que a situação-problema representava e o GeoGebra na busca dos parâmetros da função de segundo grau associada." (RE20).

Nesta mesma categoria estão os sites integrados às pesquisas de Modelagem (RE6, RE10, RE11, RE14, RE17). O direcionamento das investigações foi orientado por meio de pesquisas na Internet que permitissem ampliar os conhecimentos dos estudantes acerca do tema investigado: "os alunos deveriam utilizar um site de busca para realizar pesquisas acerca do tema" (RE14).

As plataformas do Google também constituem ferramentas muito sofisticadas para as investigações com Modelagem Matemática. A elaboração dos modelos matemáticos é favorecida pela facilidade de uso destas plataformas, pela variedade de informações e recursos num mesmo espaço. Estão os modelos associados aos relatos RE8, RE11 e RE29.

O Google Correlate relaciona termos ou palavras, permitindo ao usuário estabelecer uma correlação entre eles. No caso do relato, seu objetivo foi "utilizar o recurso Google Correlate para, em duplas ou trios, desenhar o gráfico de uma função, escolhida entre função linear, quadrática, exponencial ou logarítmica" (RE11). Os dados foram modelados por meio deste recurso e, com os resultados, foi criada a narrativa digital proposta pelo professor.

O Google Maps, empregado na visualização de mapas por meio de imagens de satélites com diversas funcionalidades, foi empregado em dois dos relatos. No primeiro identificado, "utilizou-se o Google Maps para medir as distâncias percorridas" (RE8). Já o outro buscava saber o melhor local para a abertura de um restaurante na cidade de Londrina, havendo sido utilizada a plataforma para coletar dados "como distância, tempo de caminhada, preço médio por pessoa e valor imobiliário para locação" (RE29), que seriam úteis para a determinação do local mais 
adequado ante as várias hipóteses aventadas na investigação.

O emprego de vídeos também foi expressivo na realização das atividades que constam nos relatos (RE2, RE9, RE13, RE14, RE16, RE22, RE23, RE25). Alguns foram mostrados pelo docente e outros produzidos pelos próprios estudantes. Este fato reforça a ideia de que a utilização de vídeos "proporciona uma grande quantidade de informação de maneira rápida e dinâmica". (DOMINGUES, 2014, p. 23).

Foi possível perceber que a função pedagógica dos vídeos fica bem estabelecida. Como exemplo, em um dos relatos, os autores destacam: "permitir mostrar todo o desenvolvimento do experimento empírico e não apenas os dados obtidos a partir dele, em uma associação entre tecnologias digitais, como smartphone e softwares de edição de vídeos" (RE22).

Notamos que as tabelas são utilizadas com frequência (RE2, RE8, RE9, RE10, RE18, RE19, RE21, RE28, RE29), o que corrobora a ideia de Bassanezi (2002) na organização dos dados de uma investigação no início da Modelagem. Em alguns relatos, as tabelas foram elaboradas com o auxílio de planilhas do Excel, enquanto, noutros, feitas a mão no próprio caderno dos estudantes.

O uso das tecnologias de maneira estratégica e eficiente foi verificado nas atividades expressas nos relatos. Não obstante as limitações dos espaços escolares no que se refere à sua estrutura ou à formação docente - "as professoras comentaram que ainda se sentem um pouco inseguras, pois, por vezes, 'os alunos estão melhor preparados"' (RE20) — os resultados das pesquisas se evidenciam favoráveis ao seu emprego na Modelagem Matemática.

Cabe considerar a ideia de que recursos menos sofisticados, que também contribuem para 0 aprendizado dos estudantes, são aplicados em diversas atividades de Modelagem. Em algumas ocasiões, a escolha está em consonância com a experiência docente que permite definir antecipadamente 0 recurso que melhor se harmonize ao nível dos estudantes. Em RE23, os pesquisadores optaram pelos desenhos geométricos com turmas do Ensino Infantil, enquanto em RE31 o emprego do software Tracker foi com turmas do Ensino Médio. Em RE24, por sua vez, foi útil um vídeo com alunos do Ensino Superior.

Como parte de nosso objetivo - identificar os recursos didáticos em atividades de Modelagem Matemática - observamos que os recursos assumem as características definidas anteriormente: são didáticos porque se destinam ao ensino e à aprendizagem dos conteúdos matemáticos previstos (ou não) no planejamento do professor; são pedagógicos porque têm 
finalidade educativa, buscam favorecer a aprendizagem, se adequando às necessidades dos sujeitos em atividades de Modelagem.

Analisamos, agora, as situações nas quais esses recursos, planejados ou emergentes, são inseridos no planejamento docente. Vale ressaltar que, em qualquer dos casos, não estamos fazendo opção ou tecendo críticas às escolhas dos pesquisadores. Entendemos, no entanto, que a percepção destes aspectos do planejamento de atividades com Modelagem é necessária ao professor para permitir maior segurança e possibilidades de ação.

No Quadro 3, observamos que a maioria dos recursos é do tipo planejado. Cabe considerar que na ação docente um mesmo recurso, dependendo do contexto e da realidade de investigação, é identificado como planejado ou emergente. Nos relatos em análise, gráficos, sites, softwares e aplicativos, tabelas e vídeo assumem essa condição. Os gráficos, por exemplo, foram planejados em RE21 e emergentes em RE8 e RE16. Já as tabelas foram planejadas em RE2, RE18, RE19, RE21, RE28 e emergentes em RE8, RE9, RE10 e RE29.

Quadro 3: Categorias dos recursos didáticos nos relatos de experiência (RE)

\begin{tabular}{|lll|l|}
\hline \multicolumn{3}{|c|}{ Recursos planejados } & Recursos emergentes \\
\hline Álbum de figurinhas & Folhas de jornal & Áudio (gravação) & Artigo \\
Animação & Google correlate & Desenhos & Bula de herbicida \\
Balança & Malha quadriculada & Diário de campo & Documentos \\
Bastão & Mandala & Gráfico & Material de manipulação \\
Bicicleta & Narrativa digital & História & Sacos de terra \\
Bolinhas de aço & Pipeta & Sites & Fotos \\
Cartazes & Produção textual & Instrumentos de & Entrevista \\
Cola e fita adesiva & Recortes de jornais & medida & Google Maps \\
Dado de seis faces & Relatório & Jogos & Gráfico \\
Fita métrica e trena & Sapato/altura dos alunos & Questionário & Sites \\
Folhas de jornal & Semente de pepino & Softwares e aplicativo & Softwares e aplicativos \\
Formas geométricas & Sistemas fuzzy & Tabela & Tabela \\
& & Vídeo & Vídeo \\
\hline
\end{tabular}

Fonte: Elaboração dos Autores

Nos cenários de investigação destacados em Skovsmose (2000), podemos associar 0 emprego de recursos planejados ao paradigma do exercício, ou seja, está situado na zona de conforto docente, como chama o autor, que receia os diversos cenários não contemplados no planejamento. Já os recursos emergentes podemos relacionar à zona de risco, quando o professor não consegue antecipar as questões desencadeadas pelos estudantes na investigação. 
Sendo assim, notamos que, mesmo em atividades com Modelagem Matemática, ainda persistem algumas nuanças do ensino concentrado nas ações do professor. Concorre para isto a insegurança docente com esse tipo de atividade, que passa a empregar os recursos planejados. Interessante é destacar em alguns relatos a opção pelo caso 1 (BARBOSA, 2001), no qual o professor seleciona o problema e os dados, deixando para os estudantes a responsabilidade apenas na investigação para resolução do problema (RE12), e pelo caso 2, em que o docente apenas seleciona o problema de investigação (RE2, RE14, RE18). Nos dois eventos, a escolha dos recursos didáticos dos relatos foi feita pelo professor.

Os excertos que seguem são de professores (pesquisadores) que desenvolveram as atividades de Modelagem, já estruturando os recursos didáticos no planejamento:

O professor [...] começou discutindo com os alunos sobre a chance de uma determinada situação ocorrer, como por exemplo, ganhar na megasena, se machucar cortando a grama ou a barba, virar um astronauta, entre outros. Em seguida foi exibido o vídeo intitulado "O país dos raios". (RE2).

Para a aula inicial, os grupos deveriam trazer fita métrica e trena, para realizar as medições necessárias. A primeira medição foi realizada no pátio da escola, onde os grupos, utilizando fita métrica, mediram o comprimento do pneu da bicicleta e anotaram tal informação no caderno. (RE4).

A proposta feita pelo professor regente da disciplina era que em pequenos grupos os estudantes realizassem uma pesquisa sobre termos correlacionados por meio deste aplicativo e com essas informações criassem uma narrativa real ou fictícia com 0 propósito de justificar esta correlação. (RE11).

[...] ainda que os problemas já houvessem sido formulados pela professora, primeira autora desse texto, os estudantes participaram ativamente das discussões. (RE12).

[...] propusemos uma atividade de Modelagem que deveria ser desenvolvida por meio da construção de um programa de computador, utilizando para isso o software Scratch. (RE13).

Com o objetivo de explorar a ideia de medida de área, solicitamos aos alunos que, em grupos, medissem alguns espaços da escola usando o metro quadrado por eles construído: rampas, pátios, parquinho e espaços de convivência. (RE14).

[...] as escolas nas quais foram realizadas as práticas, encontram-se com boa infraestrutura e disponibilizaram recursos tecnológicos (notebooks ou similares) para a realização do experimento. Os alunos, em sua maioria, têm smartphones com acesso à internet. (RE20).

[...] pensamos em tomar algo que fosse agradável e que pudesse incentivar futuros professores, por isso recorremos ao uso da mídia de animação "Procurando Nemo" como um material didático-pedagógico. (RE24).

No primeiro encontro eram objetivos o reconhecimento e adaptação frente ao jogo proposto para esta oficina. (RE27).

Com as informações em mãos pedi a eles que as organizassem em uma tabela (RE28).

No início da aula os alunos foram apresentados ao software Tracker, o qual todos afirmaram ainda não conhecer, e mostramos brevemente algumas de suas 
funcionalidades. (RE31).

Conforme o princípio da organização (MENDONÇA e LOPES, 2015), a obtenção do material é prevista nestes relatos desde o planejamento da atividade. Ali, também se observam as análises teórica e ambiental (SOUSA, 2015). Em RE20, por exemplo, houve a preocupação com a infraestrutura da escola e se os estudantes tinham acesso à internet e, em RE4, os pesquisadores pediram aos estudantes que trouxessem de casa os materiais que seriam utilizados na atividade.

Em alguns casos (RE2, RE9, RE14, RE31, RE32), os recursos didáticos planejados estão relacionados aos conteúdos de ensino que também são definidos antecipadamente, fato que possibilita atender o currículo escolar (CALDEIRA, 2013). Há, no entanto, relatos que estão mais afinados com a ideia de Modelagem, na qual, mediante o tema de investigação, os conteúdos são requeridos dos estudantes no decorrer da pesquisa. É o que ocorre com o RE30 que, já definida a utilização do software GeoGebra, buscou identificar os conceitos matemáticos mobilizados em atividades de Modelagem que empregam ferramentas digitais.

Alguns autores buscam justificar sua opção na ideia de Modelagem e no emprego dos recursos adotados. Um dos autores de RE12, por exemplo, tem a opção pelo caso 1 (BARBOSA, 2001), com o planejamento e recursos já estruturados, amparada em sua primeira experiência com Modelagem Matemática. Os autores de RE24, na escolha da animação "Procurando Nemo", ansiavam por algo que fosse agradável e incentivasse os sujeitos da pesquisa. Nessa mesma concepção, ou seja, da opção de planejar os recursos, percebemos que alguns autores buscavam a familiarização dos estudantes com a Modelagem Matemática, já que o relato exprime sua primeira experiência com esse tipo de atividade - RE13, RE14, RE34.

Por outro lado, identificamos em RE29 um grupo de pesquisadores com experiência na condução de atividades de Modelagem. Aqui, percebemos maior liberdade na ação e, consequentemente, o emprego de vários recursos não planejados sendo sugeridos pelos estudantes, à medida que a atividade se desenvolvia. Alguns trechos, a seguir, contidos nos relatos, evidenciam a aplicação dos recursos mediante a necessidade da pesquisa, emergindo do contexto de estudo: 
[...] com um telefonema para um dos aeroportos, tornou-se de conhecimento dos autores que no site da Rede de Meteorologia do Comando da Aeronáutica (REDEMET) era possivel ter acesso aos dados referentes à velocidade dos ventos na região. (RE6)

Fizemos a escolha de utilizar tal software por já ter familiaridade com o mesmo, visto que foi empregado em aulas da disciplina de Cálculo Diferencial e Integral I. (RE7).

[...] o grupo sentiu a necessidade de buscar por outra fonte outras informações que ajudariam a justificar suas hipóteses. Resolveram então, buscar pela internet notícias referentes ao site cifras club. (RE11).

Durante o desenvolvimento de nosso trabalho, foi encontrado 0 artigo The physics of stone skipping publicado na revista Nature. (RE16).

[...] tivemos que buscar em livros de física e sites informações que nos fornecessem 0 básico para iniciar o trabalho. (RE16).

A pedido deles [os estudantes], o professor disponibilizou o documento a partir do qual alguns dos dados apresentados na videotarefa foram obtidos. (RE22).

Diante da escolha do tema, preparamos a coleta de dados. [...] A coleta de dados aconteceu conjuntamente com as instruções da bula deste herbicida, com entrevistas a um agricultor e a um engenheiro agrônomo. (RE26).

O trecho de RE11, ao indicar a necessidade de busca dos sujeitos da pesquisa no decorrer da prática de Modelagem, mostra o que definimos como recurso emergente o que, ao mesmo tempo, caracteriza esta tendência de ensino - os conceitos explorados emergem do processo investigativo conforme a atividade acontece (BARBOSA, 2001). Também em RE22, resta evidenciada essa mesma característica quando, a pedido dos estudantes, um novo recurso é considerado na investigação.

Em RE6, os autores se referem ao software Curve Expert, necessário para a análise dos dados da pesquisa. Releva evidenciar que eles não tiveram anteriormente contato com a interface do software e, durante a modelagem do problema, precisaram organizar algum tempo para conhecê-lo. Além disso, só durante a investigação, tiveram acesso a um site que continha informações relevantes para a elaboração do modelo matemático. Em contrapartida, em RE7, os sujeitos já conheciam o software demandado durante a investigação, fato que contribuiu para sua escolha e a fim de manter o foco na obtenção do modelo matemático.

Situação semelhante pode ser observada em RE16 e RE26, quando, no desenvolvimento da atividade, emergem os recursos que irão favorecer a exploração do tema e a coleta dos dados. Em RE16, foi necessária uma pausa para adequação das informações contidas no artigo e "relacioná-lo com o que já se havia deduzido" (RE16). Em RE26, houve o momento da discussão, visando a definir um tema para posterior coleta de dados, que ocorreu, em parte, numa bula de herbicida. 
Os recursos assinalados nos relatos se mostraram úteis na exploração do tema, do ambiente de investigação e na coleta de dados, além da ampliação de conhecimentos diversos associados a outras áreas. A bula do herbicida, por exemplo, trazia dados acerca de área, volume, tempo, além de "informações médicas sobre a intoxicação [...], informações também sobre a toxicocinética, que é uma fase caracterizada como sendo a ação que o organismo realiza sobre a substância toxicante" (RE26), todas oportunas para a definição do modelo.

Vale ressaltar que a escolha do tema em alguns relatos - RE6, RE7, RE11, RE16, RE26 — foi feita pelo grupo de estudantes com orientação docente (BURAK, 1992; BARBOSA, 2001). Nestas circunstâncias, ficaram mais evidentes os recursos emergentes, já que o planejamento da atividade se iniciou com a discussão definidora do tema com sua problematização, sem ter, previamente, as fontes de pesquisa. Além disso, também surgiram conteúdos não previstos na ideia inicial de pesquisa.

A fim de superar as dificuldades na busca pelo modelo matemático, a incorporação de algum recurso foi a opção mais adequada para prosseguir com a investigação. Em RE6, os autores relatam a dificuldade na obtenção do modelo, superada com a opção por um software que facilitou o entendimento das informações. Em RE7, afirma-se que o obstáculo é a pouca assiduidade do modelador, ou seja, é preciso que atividades de Modelagem sejam desenvolvidas com maior frequência, pois, assim, "podemos encontrar algumas barreiras dentro das situações-problema que nos levam a novos transcursos não delimitados no início." (RE7).

Já em RE16, a dificuldade relacionou-se a alguns assuntos que seriam importantes na Modelagem, os quais não eram do conhecimento dos estudantes. Houve superação com a busca de recursos como livros e Internet que, segundo os autores, "além de proporcionar a oportunidade de estudar e conhecer outras áreas do conhecimento favorecendo a interdisciplinaridade, representou uma superação de desafios, pois tínhamos pouco embasamento nos conteúdos de física e inglês e não sabíamos utilizar o software Tracker." (RE16).

Então, há situações nas quais o professor flexibiliza a ação discente, sem determinar o que deve ser feito, tampouco definir a conduta dos estudantes ante o problema a ser investigado. A ação investigativa ocorrente nesses casos permite o surgimento de outras ideias, novas possibilidades para resolução do problema e, em adição, recursos didáticos que ensejam o estudo das situações manifestas sem planejamento.

Embora consideremos que quaisquer dos recursos que definimos neste texto, planejados 
ou emergentes, são importantes no fazer Modelagem, expressamos a opinião de que os recursos emergentes têm maior potencial para desenvolver o senso crítico e criativo dos estudantes. 0 professor se posta na condição de risco, mas, com isso, desloca o foco das descobertas e da pesquisa para os estudantes, fato que pode promover motivação e mais interesse pela Matemática.

\section{Considerações}

A pesquisa que desenvolvemos foi orientada por interrogações diversas: Que recursos didáticos são mobilizados em atividades de Modelagem Matemática? Em que momento da atividade eles são requeridos? Há alguma intencionalidade em seu emprego? Seu uso é planejado pelo professor? Acreditamos, mediante a análise dos relatos de experiência, ter respondido a todas elas.

Muitos recursos didáticos podem ser, e foram, efetivamente, mobilizados em atividades de Modelagem Matemática. Eles são requeridos em situações diversas do processo investigativo, sendo importantes para a exploração dos temas de investigação, como também para a coleta e análise de dados, evidenciando que cada situação-problema exige distintas abordagens e usos variados.

Quanto à intencionalidade, observamos que ela é concretizada na ação docente, conformada em selecionar recursos que se adequem ao tema definido. Há, em diversos relatos, uma associação entre os temas de investigação e os conteúdos de ensino, permitindo a opção pelos recursos que favoreçam a aprendizagem. Nem todos os recursos didáticos, todavia, são planejados na ação docente. Isso nos levou a caracterizá-los: planejados ou emergentes.

Verificamos que, quando o professor permite aos estudantes a tomada de decisão, desde a escolha do tema até a elaboração do modelo matemático, as dificuldades são subtraídas mediante as opções pelos recursos que irão desencadear novos procedimentos e outras tomadas de decisão. A "zona de risco", mencionada por Skovsmose (2000), na qual o professor se posta, ao não conseguir prever as ações e dificuldades dos estudantes ou os conteúdos e recursos didáticos que serão necessários na atividade, promove, na verdade, maior interação dos sujeitos e, consequentemente, a colaboração ocorrerá.

É oportuno ressaltar que a eficiência do recurso didático não se define por sua categoria 
planejada ou emergente. Essa categorização está associada, dentre outros fatores, a práticas docentes com a Modelagem Matemática. Professores mais experientes tendem a se arriscar mais e deixar sob responsabilidade dos estudantes todo o processo investigativo, assumindo a atitude de mediador. De efeito, a chance de os recursos serem definidos no decorrer da atividade são maiores do que em situações nas quais eles já são previamente estabelecidos.

Na prática, a atitude docente de planejar uma aula é modificada pelas estruturas da alternativa de ensino e de aprendizagem Modelagem Matemática. Tem-se a opção por manter um planejamento mais tradicional, com previsão do tema de investigação, da problemática e, junto a isso, dos recursos didáticos. Também há, contudo, a escolha de um planejamento mais fluido, conectado aos interesses discentes que, com apoio do professor, irão fazer suas escolhas incluindo as ferramentas que concedem o ensejo da elaboração do modelo matemático.

A modo de remate, procedemos a mais duas considerações acerca dos trabalhos analisados. Primeiro, no que se refere aos recursos tradicionais (livro didático, pincel e lousa), não identificamos, dentre os 33 relatos de experiência, algum que tenha recorrido a tais instrumentos. Não procedemos, nesta passagem, a nenhuma crítica que considere seu uso desfavorável em atividades de Modelagem, mas fazemos uma constatação acerca deste fato, já que estamos abordando a matéria. Muitas das atividades ocorreram em ambientes fora da sala de aula, e aquelas desenvolvidas neste espaço tiveram outros recursos à disposição dos estudantes, muitos dos quais produzidos pelos próprios professores. Sob esse aspecto, temos muito ainda a avaliar em textos posteriores a este.

Em segundo lugar, consideramos este estudo como relevante para professores que têm como opção de ensino a Modelagem Matemática. A percepção que se tem acerca dos recursos didáticos nesta tendência de ensino ainda não foi explorada em outros experimentos e, sabemos, é um fator que promove a motivação dos estudantes em sua aprendizagem. Conhecer acerca da influência das ferramentas de ensino e de aprendizagem é, por consequente, importante e necessário, especialmente quando percebemos que eles podem ser, a depender da experiência docente com Modelagem, definidos com esteio na interação dos estudantes com a situação de investigação. 


\section{Referências}

BARBOSA, Jonei Cerqueira. Modelagem Matemática e os professores: a questão da formação. Bolema, Rio Claro, v. 14, n. 15, p. 5-23, 2001.

BASSANEZI, Rodney Carlos. Ensino-aprendizagem com Modelagem Matemática. São Paulo: Contexto, 2002.

BURAK, Dionísio. Modelagem matemática: ações e interações no processo de ensinoaprendizagem. 1992. 460f. Tese (Doutorado em Educação) - Faculdade de Educação. Universidade Estadual de Campinas. Campinas.

CALDEIRA, Ademir Donizeti. Formação de professores de matemática para uma sociedade sustentável: contribuições da modelagem matemática. Revista Paranaense de Educação Matemática, Campo Mourão, v. 2, n. 2, jan./jun. 2013.

DELLA NINA, Clarissa Trojack. Modelagem Matemática e Novas Tecnologias: uma alternativa para a mudança de concepções em Matemática. 2005. 228f. Dissertação (Mestrado em Educação em Ciências e Matemática) - Escola Politécnica. Pontifícia Universidade Católica do Rio Grande do Sul. Porto Alegre.

DOMINGUES, Nilton Silveira. O papel do vídeo nas aulas multimodais de Matemática aplicada: uma análise do ponto de vista dos alunos. 2014. 128f. Dissertação (Mestrado em Educação Matemática) - Instituto de Geociências e Ciências Exatas. Universidade Estadual Paulista. Rio Claro.

EITERER, Carmen Lúcia; MEDEIROS, Zulmira. Recursos pedagógicos. In: OLIVEIRA, Dalila Andrade; DUARTE, Adriana Cancella; VIEIRA, Lívia Fraga. (Org). Dicionário: trabalho, profissão e condição docente. Belo Horizonte: FaE/UFMG, 2010, p. 1-4.

FERNANDES, Rúbia Juliana Gomes; SANTOS JÚNIOR, Guataçara dos. Modelagem matemática: um recurso pedagógico para o ensino de Matemática. Revista Práxis, Volta Redonda, v. 4, n. 8, p. 21-29, ago. 2012.

FIORENTINI, Dário; MIORIM, Maria Ângela. Uma reflexão sobre o uso dos materiais concretos e jogos no ensino da Matemática. Boletim da Sociedade Brasileira de Educação Matemática, São Paulo, n. 7, p. 5-10, 1990.

FORTUNA, Tânia Ramos. Jogo em aula: recurso permite repensar as relações de ensinoaprendizagem. Revista do Professor, Porto Alegre, v. 19, n. 75, p. 15-19, jul./dez. 2003.

FREITAS, Olga. Equipamentos e materiais didáticos. Brasília: Universidade Brasília, 2009.

GIL, Antonio Carlos. Métodos e técnicas de pesquisa social. São Paulo: Atlas, 2008.

HONORATO, Alex Henrique Alves. Atividades de Modelagem Matemática: delineando algumas compreensões. In: ENCONTRO BRASILEIRO DE ESTUDANTES DE PÓS-GRADUAÇÃO EM EDUCAÇÃO MATEMÁTICA, 19, 2015, Juiz de Fora. Anais do XIX EBRAPEM. Juiz de Fora: UFJF, 2015, p. 1-12. 
MENDONÇA, Luzinete Oliveira; LOPES, Celi Espasandin. Planejamento de atividades de Modelagem Matemática: um caminho possível. Em Teia, Recife, v. 6, n. 1, p. 1-24, 2015.

PAIS, Luiz Carlos. Uma análise do significado da utilização de recursos didáticos no ensino da Geometria. In: REUNIÃO ANUAL DA ASSOCIAÇÃO NACIONAL DE PÓS-GRADUAÇÃO E PESQUISA EM EDUCAÇÃO, 23, 2000, Caxambu. Anais da $23^{a}$ Reunião Anual da ANPEd. Rio de Janeiro: ANPEd, 2000, p. 1-16.

PASSOS, Cármen Lúcia Brancaglion. Materiais manipuláveis como recursos didáticos na formação de professores de Matemática. In: LORENZATO, Sergio. (Org.). O laboratório de ensino de Matemática na formação de professores. 2. ed. Campinas: Autores Associados, 2009, p. 77 92.

PASSOS, Ederson Oliveira; TAKANASHI, Eduardo Kojy. Recursos didáticos nas aulas de Matemática nos Anos Iniciais: critérios que orientam a escolha e 0 uso por parte de professores. Revista Brasileira de Estudos Pedagógicos, Brasília, v. 99, n. 251, p. 172-188, jan./abr. 2018.

RÊGO, Romulo Marinho do; RÊGO, Rogéria Gaudêncio do. Desenvolvimento e uso de materiais didáticos no ensino de Matemática. In: LORENZATO, Sérgio (Org.). O laboratório de Ensino de Matemática na formação de professores. 2. ed. Campinas: Autores Associados, 2009, p. 39-56.

REIS, Erisnaldo Francisco. Modelagem Matemática e Leishmaniose: proposta de ensino e de aprendizagem relacionando Biologia e Matemática. 2016. 165f. Dissertação (Mestrado em Ensino de Ciências Exatas) — Universidade do Vale do Taquari. Lajeado.

RODRIGUES, Fredy Coelho; GAZIRE, Eliane Scheid. Reflexões sobre uso de material didático manipulável no ensino de Matemática: da ação experimental à reflexão. Revemat, Florianópolis, v. 7, n. 2, p. 187-196, jul./dez. 2012.

SKOVSMOSE, Ole. Cenários para investigação. Tradução de Jonei Cerqueira Barbosa. Bolema, Rio Claro, v. 13, n. 14, 2000.

SKOVSMOSE, Ole. Desafios da reflexão em Educação Matemática Crítica. Tradução de Orlando de Andrade Figueiredo e Jonei Cerqueira Barbosa. Campinas: Papirus, 2008.

SOUSA, Francisco Edisom Eugênio de. A pergunta como estratégia de mediação didática no ensino de Matemática por meio da Sequência Fedathi. 2015. 283f. Tese (Doutorado em Educação) - Faculdade de Educação. Universidade Federal do Ceará. Fortaleza.

SOUZA, Jonimar da Silva. A utilização de recursos didáticos no ensino da Matemática: uma experiência vivenciada nas séries iniciais. Revista Olhar Científico, Ariquemes, v. 1, n. 2, p. 340350, ago./dez. 2010.

SOUZA, Salete Eduardo de. 0 uso de recursos didáticos no ensino escolar. In: SEMANA DE PEDAGOGIA DA UEM, 3, 2007, Maringá. Anais da XIII Semana de Pedagogia da UEM: Infância e Práticas Educativas. Maringá: UEM, 2007, p. 110-114.

WERLICH, Raquel. O uso da Modelagem Matemática como recurso didático-pedagógico na elaboração de experimentos para feiras de Ciências. 2008. 176f. Dissertação (Mestrado em Ensino de Ciências e Matemática) — Universidade Luterana do Brasil. Canoas. 